\title{
Disentangling Food Security from Subsistence Agriculture in Malawi
}

Todd Benson

May 2021

V/ alawi is a food-insecure country, and although most households have access to arable land, many rural Malawians cannot reliably obtain enough food to meet their dietary needs. Rainfed, low-input subsistence production, particularly of the staple crop maize, has historically been the primary means of assuring household food security. Today, most of Malawi's 4 million households continue to grow much of their own food. However, with increasing regularity, several hundred thousand households each year are vulnerable to acute food insecurity. Insufficient crop harvests resulting from poor seasonal growing conditions and limited use of inputs, coupled with reliance on shrinking landholdings as the population continues to grow and in the context of weak markets in which to sell crops and buy food, mean that subsistence farming cannot meet the dietary requirements of all Malawians.

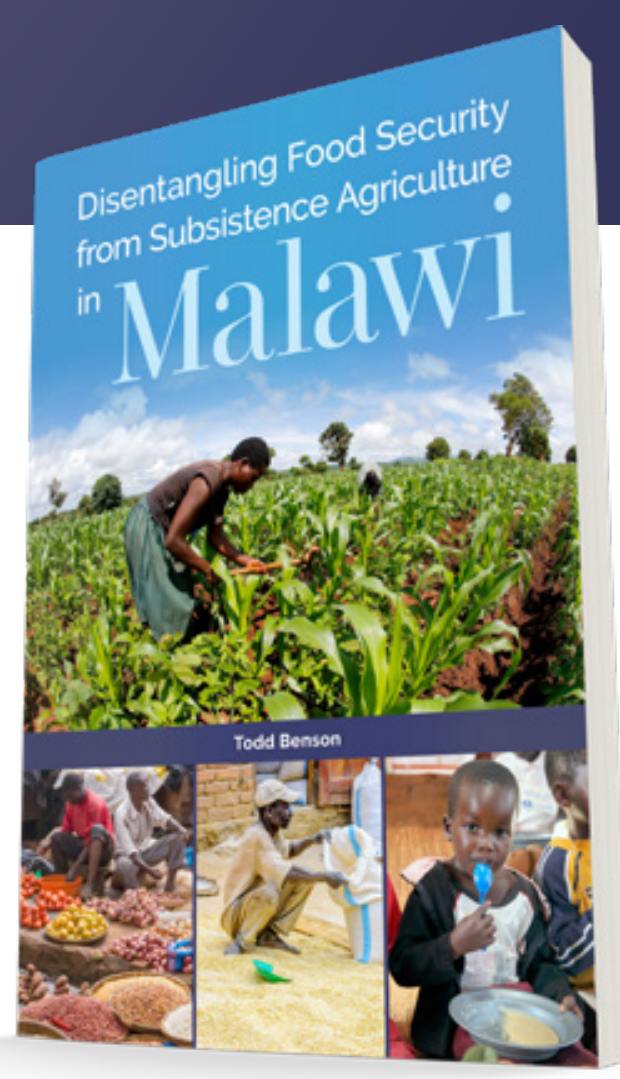

Nevertheless, the country's policy approach to food security continues to center on household agricultural production for own consumption, rather than placing agriculture in the context of broader policies for economic diversification and rural transformation. Disentangling Food Security from Subsistence Agriculture in Malawi seeks to contribute to achieving a development vision for Malawi in which everyone has access to the food they require. Achieving rural transformation will require the agriculture sector to move away from a focus on production for food self-sufficiency at both household and national levels, and toward a marketcentered, more concentrated and specialized sector that will nevertheless reliably serve the food needs of increasing numbers of Malawians working outside of the sector. Drawing on a range of conceptual approaches, the book explores data on food security, production, and agricultural markets as well as past and current policies in Malawi, and proposes a promising path toward rural transformation supported by commercially oriented farming households.

\section{Food Insecurity and Agricultural Production}

Food insecurity in Malawi is rooted in reliance on low-input crop production. First, because the country depends heavily on rainfed domestic production of maize, the amount available from each harvest is quite variable. The incidence of annual food crises affecting more than 10 percent of the population has increased in recent years (Figure 1). Second, at the household level, poverty prevails. The poverty rate has remained relatively unchanged for the past 20 years. Poverty analyses since the late 1990s have shown consistently that 50 to 55 percent of all Malawians have consumption levels below the poverty line, which is based 


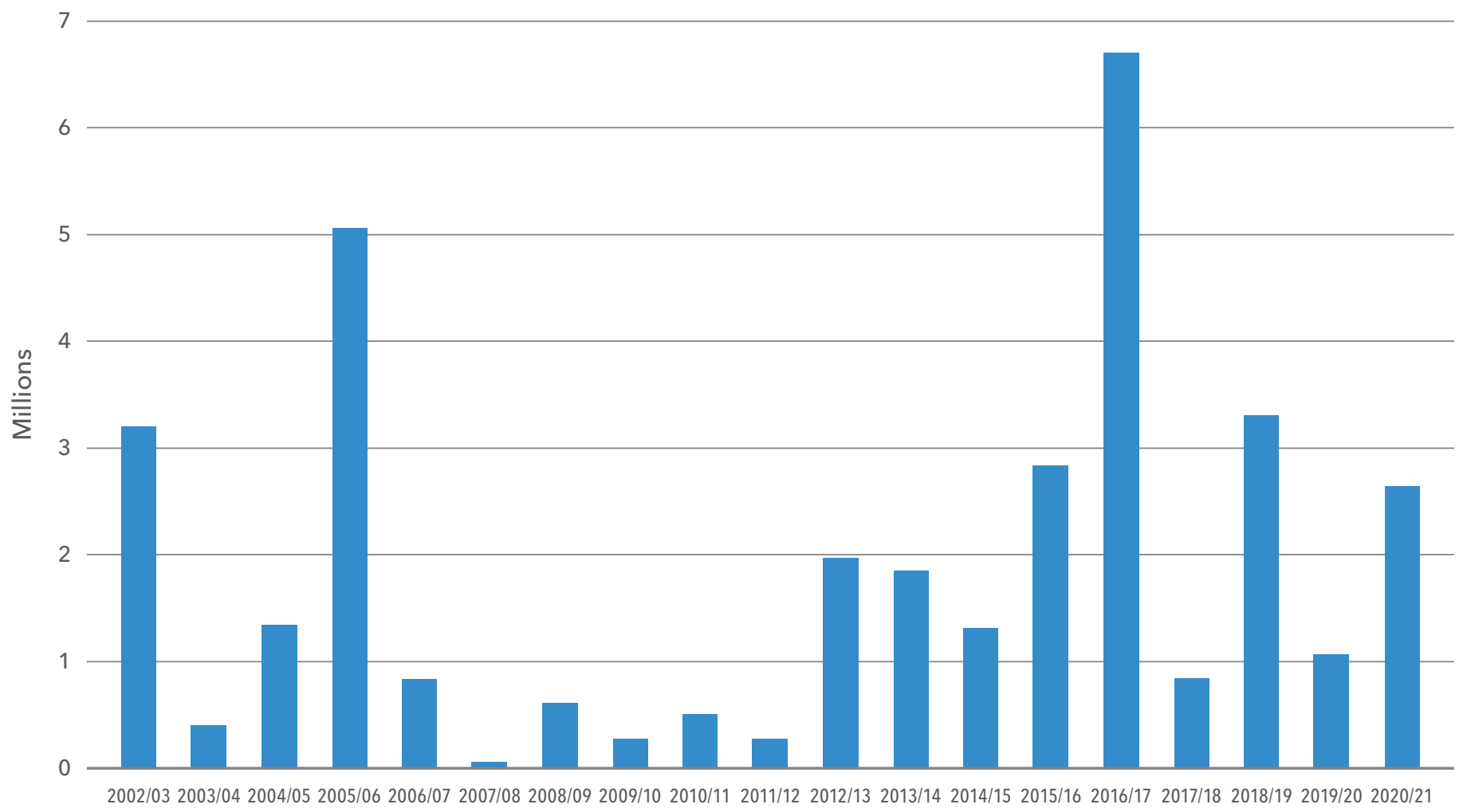

Source: Various Malawi Vulnerability Assessment Committee and Famine Early Warning Systems Network (FEWS NET) reports; National Statistical Office of Malawi population estimates and projections.

on recommended calorie requirements. These individuals do not have regular access to enough food to meet their dietary needs. Moreover, rural Malawians who are primarily engaged in farming are more likely to have deficient food consumption than the overall population.

Most rural households have access to land for food crop production. Moreover, about a third of urban households, even when primarily employed in other sectors of the economy, produce some of their own food either through peri-urban farming or by organizing food-crop production in their rural areas of origin. However, agricultural development that would increase food availability faces several obstacles in Malawi. These include the financial challenges farmers face in profitably using commercial inputs, the difficulty of food-crop diversification when farmers must rely on their own production for food, and the overriding constraint on crop productivity levels of low soil fertility. Limited use of fertilizers, despite repeated government subsidy programs, and lack of irrigation keep productivity levels low. Farmers also lack sound information that is adapted to the local context on how best to manage soil fertility for sustained higher yields. Low crop productivity plus a growing population mean that Malawian households, particularly poorer households, increasingly depend on the country's weak markets for an important share of their food, especially in the lean season before a new harvest. Once a household's food stocks from its own production are exhausted, there are few other options.

\section{Agricultural Markets}

Malawi's agricultural markets are thin with often unmatched levels of supply and demand for farm products, and consequently, prices in them are volatile. The dominant subsistence orientation of smallholder farming households and the weak agricultural markets are two halves of the same vicious cycle: Farmers with surpluses cannot be certain they will find buyers who will pay them a profitable price for their food crops. And consumers cannot be certain they will find the food they require in the market at a price they can afford. Together these risks depress traded volumes, undermine market development, and reinforce the subsistence orientation of farming households. As a result, only relatively small shares of the total production of food crops are sold.

Several other factors contribute to these market conditions. These include price shocks caused by both poor and bumper national harvests and, in times of large-scale food crises, the availability of humanitarian food aid. Government policies also play a major role. Unpredictable government restrictions on trade in maize impede the access of surplus maize producers to more competitive regional markets and 
of consumers to maize supplies from Malawi's neighbors. In addition, disruptive and generally ineffective interventions in domestic maize markets by the agricultural marketing parastatal, ADMARC, compound the problem.

As a result, maize prices in Malawi have been unpredictable both within the annual cropping cycle and between cycles during the past decade or so. These irregular price patterns increase market risks for potential commercial maize producers and for maize traders and further deter consumers from relying on the market for the maize and other foodstuffs they require, reinforcing their subsistence orientation.

\section{Policy Responses}

The agriculture sector is second to the service sector in its contribution to Malawi's GDP. But it is central to economic and human development planning, given the significant share of the population that is employed in agriculture, the importance of agricultural exports for Malawi's trade, and, most important, the critical role of subsistence agricultural production in food security. Under Malawi's current policy framework, food security remains central to priority-setting for agricultural development. The reverse relationship also holds - food security strategies for Malawi principally invoke agriculture-based solutions.

Malawi's leaders have repeatedly demonstrated that they recognize their obligation to meet the food needs of all citizens. Within the public sector, the agriculture ministry has had the heaviest responsibility for doing so, particularly through efforts to increase maize production. This is generally done in a direct manner, including through providing subsidized fertilizer and improved seed for food crops to a significant share of smallholder farming households, restricting the export of food crops, intervening in agricultural markets by setting both floor (to help producers) and ceiling (to protect consumers) prices for maize, and distributing food aid in times of acute food insecurity. However, these policies are unlikely to result in a foodsecure Malawi over the longer term. A more viable path to food security is needed that goes beyond subsistence production and the agriculture sector alone.

Strategic thinking around both agricultural development and food security should seek to move the sector away from its focus on production for food self-sufficiency at both the household and national levels and toward a market-centered, more concentrated and specialized sector that will reliably meet the food needs of increasing numbers of Malawians working outside of agriculture.

\section{Rural Economic Differentiation}

How can the vicious cycle of low productivity and weak markets be replaced by agricultural development and growing food security? Placing commercially oriented smallholder farmers at the center of rural economic transformation is a promising approach. This subset of smallholders is uniquely positioned within rural communities to serve as an engine of economic growth. Providing support to raise the productivity of these households will increase their incomes and thus their consumption of locally produced goods and services, particularly labor-intensive and generally non-transportable goods and services. This, in turn, will increase the incomes of their neighbors who produce these goods and services, thus diffusing the economic gains made by commercially oriented smallholders to other rural households. With sustained returns, many of these other households will expand their activities to serve wider markets, further increasing their incomes and, of interest here, better ensuring their access to food. Many will transition from being poor, subsistence-oriented households to become specialized in livelihoods outside of agricultural production. The deepening of local markets and acceleration of local nonfarm economic activities will improve access to food for economically active households, including the poor, in these communities. Disentangling Food Security from Subsistence Agriculture in Malawi explores several facets of this rural transformation, with the following key findings and caveats:

COMMERCIAL SMALLHOLDER LIMITATIONS. Implementing an approach centered on commercially oriented smallholder farmers will be challenging, because recent household surveys show that there are currently relatively few such households. Nevertheless, with effective market development and increased agricultural productivity, commercial smallholder farmers could grow as a share of rural households. At the same time, with stronger markets and more reliable access to food through them, other rural households will see many of the barriers and risks to adoption of nonagricultural livelihoods become less constraining.

SECTORAL TRADE-OFFS. Trade-offs across sectors will be necessary. Using a model of Malawi's economy, the outcomes of sector-focused investment options are compared. A service sector-focused development program provides the most economic growth and employment, whereas an agriculturefocused approach will be best for improving the welfare of the poor. But continued lagging growth for Malawi's economy that occurs under an agriculture-focused approach may not provide sufficient income and employment opportunities to enable many poor Malawian households to exit poverty.

ECONOMIC TRANSFORMATION. An expansion of remunerative employment in nonagricultural sectors of the economy will be needed to foster considerable movement of labor and capital into industry and services. Human capital development will be key to propelling growth in these sectors. However, bringing about such a transformation will require increased attention to raising agricultural productivity, even as a broad range of public investments are made to improve productivity in both the industry and service sectors and to expand opportunities in urban areas. 
MIGRANT LABOR. International wage-labor migration has a role to play in improving the well-being of Malawian households. The use of this livelihood option will intensify as long as a structural transformation of Malawi's economy is not achieved. Strategies should be developed now so that such migration will benefit all concerned - the migrant, his or her family in Malawi, and Malawi as a whole.

While focused on commercially oriented farming households as the engine of change, such a rural economic development strategy must not neglect the food security of other rural households in the short to medium term, even as efforts are made to enable these other households to improve their welfare through livelihoods outside of agricultural production. Food security will be best assured if Malawians can obtain good employment, whether within or outside of farming, confident that they can use their income to obtain food in significantly more reliable markets at reasonable prices. At the same time, government must ensure that households that are not economically productive receive direct support through effective social protection programs to meet their food needs.

\section{Toward a Food-Secure Malawi}

The proposed approach to sustainable food security in Malawi calls for three fundamental changes:

- Government support for the emergence of a significantly more diversified and commercially oriented agriculture sector to increase agricultural productivity and reduce volatility in food supplies with the goal of ensuring that Malawi is food secure.

\section{- Rural economic transformation, propelled by the} increased agricultural productivity of these commercially oriented smallholders, to raise incomes and increase nonfarm opportunities for all rural households.
- Strengthened food markets that are both more efficient and deeper, which are necessary to improve food security for all Malawians.

To serve as the foundation for the nation's food security, Malawi's markets will require predictable government interventions when necessary, policy stances that are supportive of agricultural market traders, and better integration into regional markets. Producers must be able to bring their output to sell in the market with confidence that they will obtain a remunerative price from a deep pool of traders and processers operating there. Correspondingly, traders should be able to draw upon a number of supply sources, primarily through increased domestic production, but also through wider sourcing from across eastern and southern Africa. The principal measure of such efforts' success in strengthening markets will be whether consumers find that they can go to the market at any time and be able to purchase all the food their household needs at an acceptable price. Without reliable markets, subsistence farming, even at low levels of productivity, will remain the main livelihood strategy for many poor Malawian households, and few will see their welfare improve.

This book directly addresses the situation in Malawi, but readers with a particular interest in similar development challenges around food insecurity, agricultural development, and economic transformation in other low-income countries, particularly in Africa, will find pertinent insights. Several of Malawi's neighbors will find the discussion of food insecurity and the suggestions for how these challenges might best be addressed to be relevant and instructive. More broadly, many of the world's developing countries that are trying to design effective development pathways to improve the livelihoods of their citizens who work in low-output, subsistence-focused agriculture will find lessons that can be adapted for their own contexts.

Todd Benson is a senior research fellow in the Development Strategy and Governance Division of the International Food Policy Research Institute (IFPRI), Washington, DC.

This synopsis is based on the peer-reviewed book Disentangling Food Security from Subsistence Agriculture in Malawi, published by the International Food Policy Research Institute, Washington, DC.

\section{Disentangling Food Security from Subsistence Agriculture in Malawi is available for free download at https://doi.org/10.2499/9780896294059.}

\section{INTERNATIONAL FOOD POLICY RESEARCH INSTITUTE \\ A world free of hunger and malnutrition \\ IFPRI is a CGIAR Research Center}

1201 Eye St, NW, Washington, DC 20005 USA | T. +1-202-862-5600 | F. +1-202-862-5606 | Email: ifpri@cgiar.org | www.ifpri.org | www.ifpri.info

DOI: https://doi.org/10.2499/9780896294073 